\title{
Model of coping with occupational stress of academics in a South African higher education institution
}

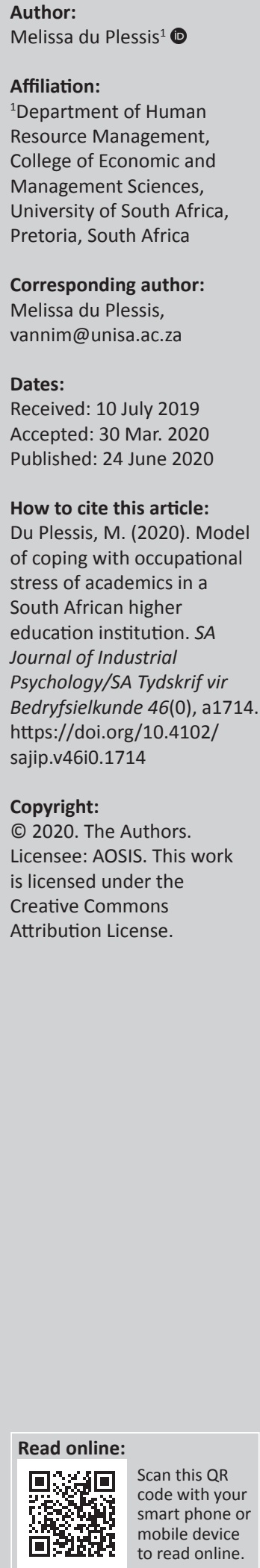

Orientation: Occupational stress is a phenomenon that affects the physiological and psychological health and well-being of academic staff in higher education institutions (HEIs).

Research purpose: The purposes of this study were: (1) to test a structural model of occupational stress and coping for academics in a South African HEI, and (2) to determine whether the proposed adaptive coping strategies positively and significantly predict coping success.

Motivation for the study: Occupational stress among academics will increase unless strategies and mechanisms are adopted to cope with the environmental demands in their profession. Higher education institutions seeking to promote academics' health and well-being should first comprehend the complexities of the coping process. There is thus a need for a more holistic view of coping with occupational stress in academia.

Research approach/design and methods: A quantitative approach, using a cross-sectional, survey design, collected 305 responses from a convenience sample of academics. The Comprehensive Coping Strategies Questionnaire (CCSQ) was administered to the participants. Statistical analyses included descriptive statistics, thematic analysis, exploratory and confirmatory factor analysis, standard multiple regression analysis and structured equation modelling.

Main findings: The theoretically hypothesised model had a good fit with the empirically manifested structural model. Academics experience both organisation- and job-specific stressors that elicit distressing emotions. Academics adopt adaptive coping strategies, which are associated with coping success.

Practical/managerial implications: Higher education institutions should implement interventions to eliminate occupational stressors and should encourage academic staff to adopt adaptive coping strategies by arranging stress management courses and Affect Regulation Training (ART).

Contribution/value-add: The study contributes toward a more holistic view of coping with occupational stress in academia, especially within a South African higher education context.

Keywords: occupational stress; coping; emotion regulation; academia; higher education.

\section{Introduction}

\section{Background to and rationale for the study}

Occupational stress is a general and global phenomenon that affects the physiological and psychological health and well-being of an individual (Rakshit \& Sharma, 2016). Academic staff in higher education institutions (HEIs) are no exception, as workplace stress among academics has increased over the past decade (Mudrak et al., 2016). The rising levels of occupational stress could be ascribed to: the substantial growth in student numbers and in the number of HEIs (Catano et al., 2010); an increased emphasis on research output (Bezuidenhout, 2015); adapting to changing curricula and quality assurance measures (Slišković \& Maslić Seršič, 2011); and keeping abreast of rapid technological advances (Jahanzeb, 2010). Hence, all domains of academia are becoming more demanding, with each academic fulfilling approximately 40 work roles, such as subject specialist, researcher and assessor, daily (Bezuidenhout, 2015).

Owing to an increase in work demands, academics are forced to work long hours, which results in a number of physiological, psychological, behavioural and organisational consequences (Kinman, 2001; Steyn \& Kamper, 2006). The reported consequences of stress on academic staff are: teaching below standard, absenteeism, conflict with students, seeking employment elsewhere 
and, ultimately, poor health and well-being (Stevenson \& Harper, 2006). Darabi, Macaskill and Reidy (2017) warn that the stressors that academics experience will continue to increase unless they and their respective institutions adopt strategies and mechanisms to cope with these demands.

Against this background, it is evident that occupational stress is a continuing concern for HEIs.

Previous research explored occupational stressors and coping strategies amongst academics in other countries (Abbas \& Roger, 2013; Ablanedo-Rosas, Blevins, Gao, Teng, \& White, 2011; Broadbent, 2013; Darabi et al., 2017; Holton, Barry, \& Chaney, 2016; Johnson, Willis, \& Evans, 2018; Poalses \& Bezuidenhout, 2018), but researchers have devoted little attention to producing a more holistic view of coping with occupational stress in a South African higher education context. Researchers have also become increasingly interested in emotional experiences during stressful life events (such as chronic illnesses), but have devoted little attention to the emotions that employees experience when confronted with occupational stressors. From a positive psychology perspective, it is important for academics to identify occupational stressors in their respective institutions and to develop solutions to eliminate them.

\section{Research purpose and objectives}

This study aims to address the shortcomings in existing literature by extending the appraisal theory of coping and emotion (Folkman \& Lazarus, 1988) to produce a more holistic view of coping with occupational stress among academics. The objective of this study was to test a structural model of occupational stress and coping for academics in a HEI in South Africa. Additionally, the study aimed to determine whether the proposed adaptive coping strategies positively and significantly predict coping success. The following research hypotheses were formulated:

H1: The theoretically hypothesised model has a good fit with the empirically manifested structural model.

H2: Adaptive coping strategies positively and significantly predict coping success.

The proposed theoretical model is illustrated in Figure 1 and will be discussed briefly in the next section.

\section{Literature review Conceptualising the constructs}

The concept of stress has been a source of immense interest over the past decades and has gradually evolved to the seminal work of Lazarus and Folkman in the 20th century (Lazarus \& Folkman, 1984). These researchers noted that stress is process oriented and transactional, encompassing appraisals, coping and emotions. From this perspective, stress is defined as the relationship between the person and the environment that is appraised as taxing or exceeding their coping resources (Lazarus \& Folkman, 1984). Similarly, occupational stress results from the individual's inability to cope with the pressures of the job because of a poor fit between their abilities and work requirements (Beheshtifar \& Nazarian, 2013). However, the perception of stress increases until the individual has made a conscious decision to cope with the stressor. Consequently, coping is defined as a conscious effort that individuals adopt to manage specific demands that are appraised as taxing or exceeding their coping resources (Lazarus \& Folkman, 1984).

\section{Antecedents of the proposed model}

\section{Occupational stress}

Many individuals perceive the organisation as a source of stress that affects their physiological and psychological health and well-being (Beheshtifar \& Nazarian, 2013; Vokić \& Bogdanić, 2008). Studies have shown that academics are exposed to various organisational stressors. Typical stressors include work overload (Mudrak et al., 2016), inappropriate deadlines (Devonport, Biscomb, \& Lane, 2008), increased student numbers (Martins \& Ungerer, 2014) and student demands (Darabi et al., 2017), pressure to publish in peerreviewed scholarly journals (Malik, Björkqvist, \& Österman, 2017), administrative tasks (Bezuidenhout, 2015), lack of resources and support services (Devonport et al., 2008), poor working conditions (Mark \& Smith, 2012), job insecurity (Safaria, Othman, \& Wahab, 2010), lack of promotion opportunities (Archibong, Bassey, \& Effiom, 2010), poor interpersonal relationships (Slišković \& Maslić Seršič, 2011), inadequate remuneration (Pienaar \& Bester, 2008) and lack of autonomy (Barkhuizen \& Rothmann, 2008).

The consequences of occupational stress in academia have been associated with job dissatisfaction, impaired work

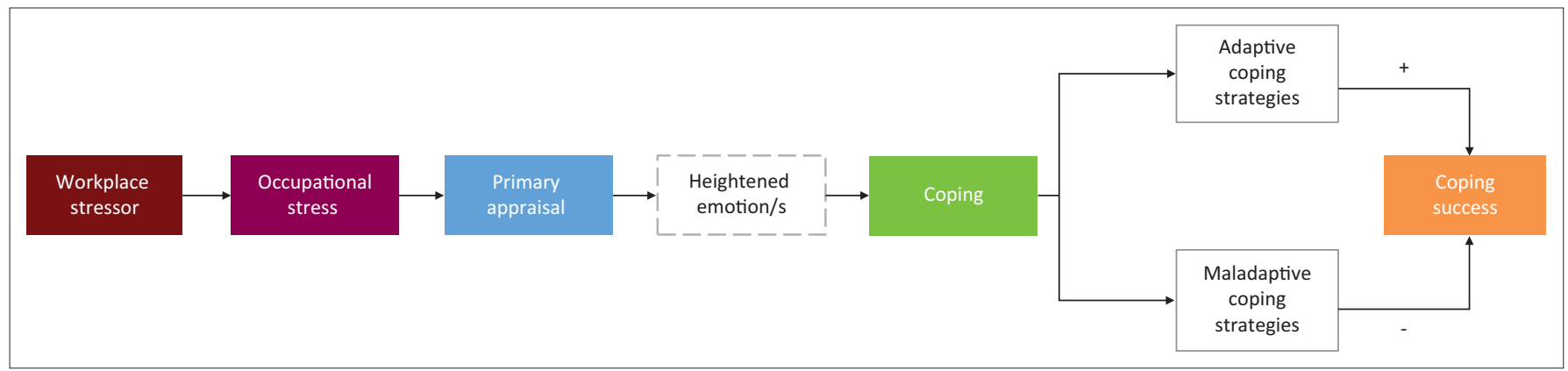

FIGURE 1: Proposed theoretical model 
performance, ill-health and poor psychological well-being, poor interpersonal relationships, absenteeism, intention to leave the institution and high staff turnover (Kinman, 2001; Pienaar \& Bester, 2008; Steyn \& Kamper, 2006). Occupational stress has also been negatively associated with the quality of the academic's family life (Slišković \& Maslić Seršič, 2011).

\section{Emotional response}

According to the appraisal theory of coping and emotion (Folkman \& Lazarus, 1988), an emotion is elicited when a workplace stressor is appraised as being a threat or challenge and harmful to the individual's health and well-being. The emotion elicited therefore depends on the cognitive appraisal of the significance of the person-environment relationship for the individual's well-being and available coping resources (Folkman \& Lazarus, 1988). Primary appraisal is thus essential to understand the cause of the emotional response being elicited.

If an emotion is elicited, it has to be regulated to modify the magnitude and type of emotional experience. Emotional responses are experienced because of the individual's inability to regulate his or her emotions. Coping and regulatory strategies are adopted to respond to the felt emotion and to modulate the individual's perception of the stressor (Schmidt, Tinti, Levine, \& Testa, 2010). From this perspective, coping is thus perceived as a mediator of the emotional response (Schmidt et al., 2010).

\section{Coping strategies}

A coping strategy is an adaptive or maladaptive response to a stressor (Aldao, Nolen-Hoeksema, \& Schweizer, 2010). Adaptive strategies are positively associated with affect modulation and physiological and psychological health and well-being. Adaptive coping strategies are thus able to modulate felt emotions so that the individual's perception of the stressor is changed (i.e. coping success).

Adaptive coping strategies include (Du Plessis \& Martins, 2019):

- Cognitive coping includes the cognitive processes of acquiring knowledge and understanding through thought and experiences, to manage the intake of emotion-arousing stimuli. Strategies include, for example, cognitive restructuring, acceptance and problem-solving.

- Emotional coping is the subjective, psychological and physiological expression and reaction to stressful encounters that are appraised as taxing or exceeding an individual's coping resources. Examples include emotional expression and processing.

- Social support coping is the perceived support that individuals receive from their social support network (e.g. family, friends and co-workers) or personal relationships.

- Leisure coping includes physical activities that individuals voluntarily engage in to regulate heightened emotions in response to environmental demands. Leisure coping include passive leisure, active leisure, social leisure activities and vacation time.

- Religious coping is defined as 'ways of understanding and dealing with negative life events that are related to the sacred' (Pargament \& Raiya, 2007, p. 743), and includes organisational and non-organisational religious activities.

Maladaptive coping strategies are associated with increased psychological distress and occupational stress, and consequently with disorders such as anxiety, depression and burnout (Karekla \& Panayiotou, 2011; Mark \& Smith, 2012; Newman \& Llera, 2011). Individuals who engage in maladaptive coping strategies continue to reappraise the stressor (because the negative emotional experience is not altered) until they are able to adopt adaptive coping strategies. Experiential avoidance (EA) is an example of a maladaptive coping strategy (Du Plessis \& Martins, 2019), and is defined as an activity that individuals engage in to alter the form and frequency of any aversive experience and distress (Hayes, Strosahl, \& Wilson, 1999). Four EA coping strategies were identified by Du Plessis and Martins (2019):

- Expressive suppression is defined as the conscious suppression of emotions.

- Thought suppression is defined as a conscious cognitive avoidance strategy that individuals adopt when actively atempting to suppress unwanted thoughts or feelings.

- Avoidant coping is defined as an individual's cognitive and behavioural attempt to avoid or escape from having to deal with a situation, a person, an emotion, a thought or any entity that causes harm. Avoidant coping strategies include self-destructive behaviour, behavioural, social and religious disengagement.

- Rumination is a method of responding to distress that involves repetitively and passively focusing on the causes, symptoms and consequences of distress.

Research findings indicate that academics adopt both adaptive and maladaptive coping strategies to respond to occupational stressors. Adaptive strategies, such as active planning (Kersh, 2018; Ladebo \& Oloruntoba, 2005), problem solving (Mark \& Smith, 2012; Mate Siakwa, 2014), positive reappraisal (Mate Siakwa, 2014), time management (Iqbal \& Kokash, 2011), seeking social support (Darabi et al., 2017; Devonport et al., 2008; Mate Siakwa, 2014), and exercise and relaxation (Holton et al., 2016) were reported. Maladaptive strategies such as using alcohol and eating more than usual (Holton et al., 2016), avoidance coping (Odirile, Mpofu, \& Montsi, 2009; Mate Siakwa, 2014) and social disengagement (Ladebo \& Oloruntoba, 2005) were also reported. Maladaptive coping strategies are, therefore, associated with poor health and well-being (Holton et al., 2016).

\section{Research design Research approach}

For this exploratory study, a non-experimental, cross-sectional, quantitative survey design was used to achieve the research objectives. A quantitative approach was chosen to collect data 
via self-administered questionnaires to determine if there was a good fit between the empirically manifested structural model and the theoretically hypothesised model. The data was collected at a single point in time (Babbie, 2010).

\section{Research method}

\section{Research participants}

The participants comprised a non-probability sample of 305 academics $(N=4016)$ who were permanently employed in a HEI in the Gauteng province of South Africa. The sample was predominantly comprised of female $(64.3 \%)$ academics $(65.9 \%)$ with a median age of 45.5 who had been employed in the higher education sector for more than 10 years $(62.0 \%)$. These academics were employed as either lecturers (24.3\%) or senior lecturers $(21.3 \%)$ who had obtained a master's $(35.7 \%)$ or doctoral $(34.4 \%)$ degree.

\section{Measuring instrument}

A measuring instrument, the Comprehensive Coping Strategies Questionnaire (CCSQ) developed by Du Plessis and Martins (2019), was deductively developed to achieve the objectives of this study. The questionnaire is a selfreporting instrument that consists of two sections. Section A consists of four questions that measure occupational stress. Participants were required to: (1) identify and describe a jobspecific stressor; (2) classify the stressor as academic, research or administrative-related; (3) indicate the intensity of the stressor on a 10-point sliding scale ( 1 = slightly stressful; $10=$ extremely stressful); and (4) indicate what emotion(s) they had experienced when confronted with the stressor. Section $B$ required participants to indicate whether they had used specific coping strategies to deal with the stressor identified in Section A. Section B consists of 69 items that measure six different coping strategies, namely cognitive coping (15 items), emotional coping (4 items), social support coping (8 items), leisure coping (11 items), religious coping (9 items) and EA (22 items) (Du Plessis \& Martins, 2019). Participants had to rate each item on a six-point agreement scale where 1 represented strongly disagree and 6 strongly agree.

\section{Research procedure}

The contact details of the academics were requested from the university's human resources department. The questionnaire was uploaded in English onto an online survey application, which generated a URL link. The URL link to the questionnaire and instructions on how to complete the questionnaire were copied into an electronic mail, which was sent to the participants. The link redirected the respondents to the online platform where their responses were captured. Informed consent was obtained, and confidentiality and anonymity were assured. The researcher further assured the participants in writing that the data would be used for research purposes only.

\section{Statistical analysis}

Primary data were captured, scrutinised for missing values or unengaged responses and processed. Data were processed using SPSS version 24 (IBM Corp., 2015) software. The statistical analyses included descriptive analysis, thematic analysis, exploratory and confirmatory factor analysis, standard multiple regression analysis and structured equation modelling (SEM).

Thematic analysis, which is a type of qualitative analysis, was used to classify the job-specific stressors that the participants perceived as stressful into categories or themes. The data was analysed following the three-phased process as proposed by Elo and Kyngäs (2008).

Exploratory factor analysis (EFA) was used to explore the underlying dimensionality of the instrument as suggested by Watkins (2018). Maximum-likelihood extraction and principal axis factoring (PAF) with oblique rotation (promax) was used to correlate and rotate the factor structure. Oblique rotation was preferred because it revealed more meaningful theoretical factors (Furr, 2011). Kaiser's criterion (eigenvalues for each factor $\geq 1$ ), a screen test and percentage of variance explained ( $\geq 60 \%$ ) were used to determine the number of factors. Confirmatory factor analysis (CFA) was used to confirm the factor structure and assess the internal consistency of the instrument. Internal consistency was demonstrated by Cronbach alpha coefficients.

Standard multiple regression analysis, a multivariate method, was used to determine how well a set of independent variables (namely, the coping strategies) was able to predict coping success, and to determine which variable was the best predictor of coping success. Lastly, SEM was performed to determine the extent to which the hypothesised theoretical model was supported by the empirical data (Salkind, 2010). The chi-square statistics $\left(\chi^{2}\right)$ (test of absolute model fit), the magnitude of the standardised path coefficient estimates between the independent and dependent variables and the results of the standard multiple regression analysis were used to empirically test the hypothesised relationships.

\section{Ethical consideration}

The researcher obtained ethical clearance and permission from the university's research and ethics committees. Ethical clearance (2014/CEMS/IOP/025) and permission (2017_ RPSC_011) to conduct the research was obtained from the University of South Africa.

\section{Results \\ Thematic analysis}

A deductive approach was followed to code the data into categories. Literature on the sources of occupational stress, and more specifically the sources that academics experience, was used to develop a categorisation matrix. Frequencies were calculated to determine the prevalence of the codes across the dataset and in relation to each category. The participants were also required to classify their identified stressor as being related to academic, administrative or 
research conditions (classification of the stressor), and to indicate on a sliding scale of 1 to 10 ten ( 1 = slightly stressful; $10=$ extremely stressful) how stressful the stressor was for them. These results are summarised in Table 1.
The frequency distribution and mean scores of the jobspecific stressors that the participants in the sample perceived as stressful are reported in Table 1. The results indicate that $17.8 \%$ of the participants perceived organisation-specific

TABLE 1: Results of the thematic content analysis

\begin{tabular}{|c|c|c|c|c|c|c|c|c|c|c|c|c|c|}
\hline \multicolumn{2}{|c|}{ Occupational stressor } & \multicolumn{10}{|c|}{ Classification of the stressor } & \multirow{2}{*}{\multicolumn{2}{|c|}{$\begin{array}{l}\text { Intensity of the } \\
\text { stressor * }\end{array}$}} \\
\hline & & \multicolumn{2}{|c|}{ Academic } & \multicolumn{2}{|c|}{ Admin } & \multicolumn{2}{|c|}{ Research } & \multicolumn{2}{|c|}{ Other } & \multicolumn{2}{|c|}{ Total } & & \\
\hline & & Frequency & $\%$ & Frequency & $\%$ & Frequency & $\%$ & Frequency & $\%$ & Frequency & $\%$ & Mean & SD \\
\hline 1. & Organisation-specific stressors & & & & & & & & & & & & \\
\hline 1.1 & Inadequate salaries & - & - & 1 & 0.70 & - & - & - & - & 1 & 0.30 & 9.00 & - \\
\hline 1.2 & Job insecurity & - & - & 1 & 0.70 & - & - & 1 & 1.70 & 2 & 0.70 & 9.50 & 0.707 \\
\hline 1.3 & Leadership style & - & - & - & - & - & - & - & - & - & - & - & - \\
\hline 1.3.1 & Poor leadership skills & 2 & 3.10 & 4 & 2.60 & - & - & 1 & 1.70 & 7 & 2.30 & 7.71 & 1.496 \\
\hline 1.3 .2 & Poor communication & 3 & 4.70 & 8 & 5.30 & 1 & 3.20 & 1 & 1.70 & 13 & 4.30 & 8.15 & 1.144 \\
\hline 1.4 & Organisational change & - & - & 1 & 0.70 & - & - & - & - & 1 & 0.30 & 7.00 & - \\
\hline 1.5 & Organisational culture & - & - & - & - & - & - & - & - & - & - & - & - \\
\hline 1.6 & Organisational structure & 1 & 1.60 & 1 & 0.70 & - & - & - & - & 2 & 0.70 & 10.00 & 0 \\
\hline 1.7 & Physical work environment & - & - & - & - & - & - & - & - & - & - & - & - \\
\hline 1.7 .1 & Poor work environment & - & - & 2 & 1.30 & - & - & 4 & 6.80 & 6 & 2.00 & 9.00 & 0.894 \\
\hline 1.7 .2 & Changing office locations & - & - & 1 & 0.70 & - & - & 1 & 1.70 & 2 & 0.70 & 8.50 & 0.707 \\
\hline 1.8 & Policies and procedures & - & - & 7 & 4.60 & - & - & - & - & 7 & 2.30 & 7.86 & 1.676 \\
\hline 1.9 & Protest action & 1 & 1.60 & 8 & 5.30 & - & - & 3 & 5.10 & 12 & 3.90 & 8.75 & 1.545 \\
\hline 1.10 & Financial well-being of the institution & - & - & 1 & 0.70 & - & - & - & - & 1 & 0.30 & 9.00 & - \\
\hline \multicolumn{2}{|c|}{ Subtotal of the organisation-specific stressors } & 7 & 11.00 & 35 & 23.30 & 1 & 3.20 & 11 & 18.70 & 54 & 17.80 & - & - \\
\hline \multicolumn{14}{|c|}{ 2. Job-specific stressors } \\
\hline 2.1 & Factors intrinsic to the job & - & - & - & - & - & - & - & - & - & - & - & - \\
\hline 2.1 .1 & Work overload & 15 & 23.4 & 27 & 17.90 & 10 & 32.30 & 21 & 35.60 & 73 & 23.90 & 7.73 & 1.660 \\
\hline 2.1 .2 & Administrative tasks & 4 & 6.30 & 19 & 12.60 & - & - & 1 & 1.70 & 24 & 7.90 & 8.13 & 1.296 \\
\hline 2.1 .3 & Lack of or inadequate resources & - & - & 6 & 4.00 & - & - & 2 & 3.40 & 8 & 2.60 & 8.25 & 1.669 \\
\hline 2.1 .4 & Demanding students & 4 & 6.30 & 5 & 3.30 & - & - & 1 & 1.70 & 10 & 3.30 & 7.30 & 3.302 \\
\hline 2.1 .5 & Uncooperative students & 1 & 1.60 & - & - & - & - & - & - & 1 & 0.30 & 7.00 & - \\
\hline 2.1 .6 & Pressure to publish & 2 & 3.10 & - & - & 1 & 3.20 & - & - & 3 & 1.00 & 7.00 & 2.646 \\
\hline 2.1 .7 & Time pressure & 17 & 26.60 & 15 & 9.90 & 3 & 9.70 & 5 & 8.50 & 40 & 13.10 & 7.43 & 1.796 \\
\hline 2.2 & Organisational roles & - & - & - & - & - & - & - & - & - & - & - & - \\
\hline 2.2 .1 & Role ambiguity & - & - & - & - & - & - & - & - & - & - & - & - \\
\hline 2.2 .2 & Role conflict & - & - & 1 & 0.70 & - & - & 1 & 1.70 & 2 & 0.70 & 9.00 & 1.414 \\
\hline 2.2 .3 & Routine work & - & - & - & - & - & - & 1 & 1.70 & 1 & 0.30 & 7.00 & - \\
\hline 2.2 .4 & Conflict & - & - & - & - & - & - & 1 & 1.70 & 1 & 0.30 & 8.00 & - \\
\hline 2.2 .5 & Managing a group of individuals & - & - & - & - & 1 & 3.20 & - & - & 1 & 0.30 & 9.00 & - \\
\hline 2.3 & Career development or progression & - & - & - & - & - & - & - & - & - & - & - & - \\
\hline 2.3 .1 & Over-promotion & 1 & 1.60 & 4 & 2.60 & 2 & 6.50 & - & - & 7 & 2.30 & 6.29 & 1.799 \\
\hline 2.3 .2 & Under-promotion & - & - & 1 & 0.70 & - & - & 1 & 1.70 & 2 & 0.70 & 5.50 & 2.121 \\
\hline 2.3 .3 & Employee recognition & 4 & 6.30 & 1 & 0.70 & 1 & 3.20 & - & - & 6 & 2.00 & 7.50 & 2.429 \\
\hline 2.3 .4 & Progression with own studies & 2 & 3.10 & 1 & 0.70 & 10 & 32.30 & - & - & 13 & 4.30 & 8.31 & 1.251 \\
\hline 2.4 & Interpersonal relationships & - & - & 1 & 0.70 & - & - & - & - & 1 & 0.30 & 8.00 & - \\
\hline 2.4 .1 & $\begin{array}{l}\text { Poor interpersonal relationship with } \\
\text { management }\end{array}$ & 1 & 1.60 & 4 & 2.60 & - & - & 4 & 6.80 & 9 & 3.00 & 8.56 & 1.740 \\
\hline 2.4 .2 & $\begin{array}{l}\text { Poor interpersonal relationship with } \\
\text { colleagues }\end{array}$ & - & - & 2 & 1.30 & - & - & - & - & 2 & 0.70 & 7.00 & 0 \\
\hline 2.5 & Lack of support & - & - & 2 & 1.30 & - & - & - & - & 2 & 0.70 & 8.50 & 2.121 \\
\hline 2.5 .1 & Lack of support from management & - & - & 7 & 4.60 & 1 & 3.20 & - & - & 8 & 2.60 & 8.25 & 1.669 \\
\hline 2.5 .2 & Lack of support from colleagues & 3 & 4.70 & 3 & 2.00 & - & - & 1 & 1.70 & 7 & 2.30 & 7.14 & 1.952 \\
\hline 2.5 .3 & $\begin{array}{l}\text { Lack of support from support } \\
\text { departments }\end{array}$ & 2 & 3.10 & 13 & 8.60 & 1 & 3.20 & 1 & 1.70 & 17 & 5.60 & 7.59 & 1.460 \\
\hline 2.6 & Isolation and unfair treatment & - & - & - & - & - & - & - & - & - & - & - & - \\
\hline 2.6 .1 & Harassment & - & - & - & - & - & - & - & - & - & - & - & - \\
\hline 2.6 .2 & Discrimination & - & - & - & - & - & - & 1 & 1.70 & 1 & 0.30 & 10.00 & - \\
\hline 2.6 .3 & Threats of violence & - & - & - & - & - & - & - & - & - & - & - & - \\
\hline 2.6 .4 & Bullying & 1 & 1.60 & 4 & 2.60 & - & - & 3 & 5.10 & 8 & 2.60 & 9.13 & 0.835 \\
\hline 2.7 & The work-home interface & - & - & - & - & - & - & - & - & - & - & - & - \\
\hline 2.7 .1 & Work-family conflict & - & - & - & - & - & - & 2 & 3.40 & 2 & 0.70 & 8.50 & 2.121 \\
\hline 2.8 & Other & - & - & - & - & - & - & 2 & 3.40 & 2 & 0.70 & 7.00 & 2.828 \\
\hline \multicolumn{2}{|c|}{ Subtotal of the job-specific stressors } & 57 & 89.30 & 116 & 7.60 & 30 & 96.80 & 48 & 81.50 & 251 & 82.50 & - & - \\
\hline \multicolumn{2}{|c|}{$\begin{array}{l}\text { Total of organisational - and job-specific } \\
\text { stressors }\end{array}$} & 64 & 100.00 & 151 & 100.00 & 31 & 100.00 & 59 & 100.00 & 305 & 100.00 & 7.88 & 1.713 \\
\hline
\end{tabular}

*, The intensity of the stressor was measured on a 10-point sliding scale. 
stressors as stressful (group mean $=8.59$ ). More specifically, $6.6 \%$ of the participants indicated that they perceived the leadership style of their supervisor or line manager (poor leadership skills [2.3\%] and poor communication [4.3\%]) as a potential source of stress (group mean $=7.93$ ), which caused them to become frustrated (80\%) with management. Secondly, the \#FeesMustFall protest action on university campuses in South Africa in 2016 had caused 3.9\% of the participants to experience occupational stress (group mean $=8.75$ ), which had caused them to feel anxious (83\%), frustrated (75\%) and helpless $(75 \%)$. Lastly, the results revealed that the organisation-specific stressors were mostly administration related $(64.8 \%)$.

The majority $(82.5 \%)$ of the participants perceived jobspecific stressors as demands that taxed or exceeded their coping resources (group mean $=7.84$ ). A total of $52.1 \%$ of the participants further indicated that factors intrinsic to the job, especially work overload $(23.9 \%)$, time pressure $(13.1 \%)$ and administrative tasks $(7.9 \%)$ had caused them to experience occupational stress (group means $=7.73,7.43$, and 8.13, respectively). These stressors were further classified as administration related (45.2\%). Twenty-eight $(9.3 \%)$ of the participants indicated that career development or progression, especially progression with their own studies $(4.3 \%)$, had caused them to experience relatively high levels of occupational stress (group mean $=8.31$ ), which were mostly research related $(76.9 \%)$. Thirty-four $(11.2 \%)$ of the participants indicated that a lack of support, especially from support departments (5.6\%), management $(2.6 \%)$ and colleagues $(2.3 \%)$ had resulted in moderate to high levels (group means $=7.59,8.25$ and 7.14, respectively) of occupational stress that were mostly administration related $(73.5 \%)$. Lastly, $4.0 \%$ of the participants indicated that poor relationships, especially with management (3.0\%) had caused them to experience occupational stress (group mean $=8.56$ ).

The results further revealed that job-specific stressors had caused participants to experience frustration (63\%), anxiousness (57\%), anger (38\%), irritability (37\%) and helplessness (34\%) which were mostly administration related (46.2\%).

Lastly, two participants' responses were classified as 'Other' (occupational stressor 2.8) because the identified stressors could not be grouped under any subcategory.

\section{Exploratory and confirmatory factor analysis Exploratory factor analysis}

The responses to the 69 items were correlated and rotated using maximum-likelihood extraction with oblique rotation (promax). Initial eigenvalues indicated that the first 15 factors explained $67.5 \%$ of the total variance.

When compared to the dimensions proposed by Du Plessis and Martins (2019), the results of the initial EFA clearly overestimated the number of factors for the dataset. Several items in the rotated factor matrix cross-loaded on more than one factor. These were removed, starting with the highest ratio of loadings on the variables with the highest loading. In addition, items with low factor loadings $(\leq 0.35)$ and high cross-loadings (less than 0.20 difference) in each factor were removed (Hair, Black, Babin, \& Anderson, 2010). Only 42 items were retained, which were subjected to a second round of EFA.

The 42-item instrument was subjected to a principal axis factoring (PAF). Prior to performing PAF, the suitability of data for factor analysis was assessed. Inspection of the correlation matrix revealed the presence of many coefficients of 0.30 and above. The Kaiser-Meyer-Olkin value was 0.86 , exceeding the recommended value of 0.60 (Kaiser, 1970, 1974), and Bartlett's Test for Sphericity (Bartlett, 1954) reached statistical significance $(p \leq 0.05)$, supporting the factorability of the correlation matrix.

Principal axis factoring revealed the presence of nine components with eigenvalues exceeding 1, explaining $70.4 \%$ of the total variance. An inspection of the scree plot revealed a clear break after the ninth component.

Using Catell's (1966) scree test, it was decided to retain the nine components for further investigation. To aid in the interpretation of the components, oblique rotation (promax) was performed. The rotated solution revealed the presence of a simple structure, with the nine components showing a number of strong loadings and all variables loading substantially on only one component.

\section{Confirmatory factor analysis}

The initial baseline model had a poor to mediocre fit with the following indices: the goodness-of-fit index (GFI) obtained was 0.78 (prescribed threshold $>0.90$ ) and the adjusted goodness-of-fit (AGFI) was 0.75 (prescribed threshold >0.90). The normed fit index (NFI), relative fit index (RFI), comparative fit index (CFI) and Tucker Lewis index (TLI) were $0.79,0.77,0.87$ and 0.85 , respectively, compared to the recommended level of 0.90 and higher (Baumgartner \& Homburg, 1996). The root mean square error of approximation (RMSEA) was 0.07, which was above the recommended limit of 0.06 (Hu \& Bentler, 1999), and the root mean square residual (RMR) was above the recommended threshold of 0.02 at $0.16(\mathrm{Hu} \&$ Bentler, 1999). The theorised model therefore did not fit the observed data well. Modification indices and standard residual covariance were assessed to remedy the discrepancies between the proposed and estimated model.

The revised model had a good fit with the following fit statistics reported in Table 2: all the statistics were in line with the prescribed threshold outlined by $\mathrm{Hu}$ and Bentler (1999), where CMIN $/ d f<3$, GFI > 0.90, AGFI > 0.90, CFI > 0.95, RMSEA $<0.06$, and PCLOSE $>0.05$. As this data should not be viewed in isolation, the validity and reliability of the 
TABLE 2: Model fit: Revised model.

\begin{tabular}{lcc}
\hline Goodness-of-fit (GOF) statistic & $\begin{array}{c}\text { Revised } \\
\text { model }\end{array}$ & $\begin{array}{c}\text { Prescribed } \\
\text { threshold }\end{array}$ \\
\hline Absolute fit indices & 820.75 & - \\
Chi-square (CMIN) & 459 & - \\
Degrees of freedom (df) & 1.79 & $<3=$ Good \\
Chi-square/df (CMIN/df) & 0.87 & $>0.90$ \\
Goodness-of-fit index (GFI) & 0.84 & $>0.90$ \\
Adjusted goodness-of-fit index (AGFI) & 0.05 & $\leq 0.06$ \\
Root mean square error of approximation (RMSEA) & 0.11 & $<0.02$ \\
Root mean square residual (RMR) & 0.05 & $\leq 0.08$ \\
Standardised root mean square residual (SRMR) & 0.00 & $<0.05$ \\
PCLOSE & & \\
Relative fit indices & 0.87 & $\geq 0.90$ \\
Normed fit index (NFI) & 0.85 & $\geq 0.90$ \\
Relative fit index (RFI) & 0.93 & $\geq 0.90$ \\
Tucker Lewis index (TLI) & 0.94 & $>0.90=$ Good \\
Comparative fit index (CFI): &
\end{tabular}

CMIN/df, chi-square/degrees of freedom; PCLOSE, Test of close fit.

TABLE 3: Reliability and validity estimates: Revised model.

\begin{tabular}{lcccc}
\hline Variable & CR & AVE & MSV & ASV \\
\hline RUM & 0.79 & 0.66 & 0.49 & 0.85 \\
SOC & 0.91 & 0.67 & 0.24 & 0.95 \\
REL & 0.92 & 0.67 & 0.16 & 0.97 \\
COG & 0.87 & 0.52 & 0.3 & 0.98 \\
ACT LEI & 0.88 & 0.72 & 0.18 & 0.98 \\
VAC TIME & 0.86 & 0.67 & 0.18 & 0.98 \\
AVOID & 0.78 & 0.55 & 0.49 & 0.98 \\
SOC DIS & 0.85 & 0.65 & 0.29 & 0.99 \\
EMO & 0.72 & 0.56 & 0.24 & 0.99
\end{tabular}

$\mathrm{CR}$, composite reliability; AVE, average variance extracted; MSV, maximum shared variance; ASV, average shared variance; RUM, rumination; SOC, social support coping; REL, religious coping; COG, cognitive coping; ACT LEI, active leisure coping; VAC TIME, vacation time; AVOID, avoidant coping; SOC DIS, social disengagement; EMO, emotional coping.

revised model were evaluated for each separate dimension, as indicated in Table 3.

Since the reliability (CR) for all the constructs was above the recommended threshold of 0.70 (Hair et al., 2010), all the constructs were retained. The convergent reliability (AVE) for all the constructs was above the recommended 0.50 (Hair et al., 2010), and was thus retained in the model. The discriminant validity (MSV and ASV) for all the constructs fell within the recommended threshold, where MSV < AVE and ASV < AVE (Hair et al., 2010). Considering the goodnessof-fit results and reliability and validity results, the revised model was accepted.

The results provided supportive evidence for Hypothesis 1, in that the theoretically hypothesised model had a good fit with the empirically manifested structural model.

\section{Standard multiple regression analysis}

The F-test was used to test whether there was a significant regression between the independent variables (coping strategies) and the dependent variable (coping success). Collinearity diagnostics were examined to ensure that the variance inflation factors (VIF) did not exceed 10, that the condition index was below 15 , and that the tolerance values were close to 1.0 (Field, 2013).
TABLE 4: Multiple regression analysis $(n=305)$.

\begin{tabular}{lcccccc}
\hline Variable & \multicolumn{3}{c}{ Standardised coefficient } & & \multicolumn{2}{c}{ Collinearity statistics } \\
\cline { 2 - 3 } \cline { 7 - 7 } & Beta $(\boldsymbol{\beta})$ & $\boldsymbol{t}$ & $\boldsymbol{p}$-value & & Tolerance & VIF \\
\hline SOC & 0.172 & 5.544 & $0.002 * *$ & & 0.737 & 1.357 \\
REL & 0.024 & 3.121 & 0.664 & & 0.770 & 1.299 \\
COG & 0.249 & 0.435 & $0.000 *$ & & 0.727 & 1.376 \\
ACT LEI & 0.000 & 4.477 & 0.996 & & 0.764 & 1.310 \\
VAC TIME & 0.100 & 0.005 & $0.058^{* * *}$ & & 0.808 & 1.237 \\
AVOID & -0.146 & 1.905 & $0.019 * *$ & & 0.591 & 1.692 \\
SOC DIS & -0.140 & -2.368 & $0.011^{* *}$ & & 0.745 & 1.342 \\
RUM & -0.115 & -2.549 & $0.055^{* * *}$ & & 0.635 & 1.574 \\
EMO & 0.073 & -1.927 & 0.193 & & 0.709 & 1.410 \\
\hline
\end{tabular}

Note: Model fit: $\mathrm{R}^{2}=0.337$; ANOVA $\mathrm{F}(p)=16.674(0.000)^{* * *}$.

$*, p<0.001 ; * *, p<0.05 ; * * *, p<0.10$.

SOC, social support coping; REL, religious coping; COG, cognitive coping; ACT LEI, active leisure coping; VAC TIME, vacation time; AVOID, avoidant coping; SOC DIS, social disengagement; RUM, rumination; EMO, emotional coping.

The significant results of the multiple regression analysis are summarised in Table 4 . The model was statistically significant ( $\mathrm{F} p \leq 0.05)$, with the model accounting for $33 \%$ $\left(R^{2}=0.33\right)$ of the variance in coping success. These results were moderate to large in practical effect. In terms of relative importance, coping success was mostly explained by cognitive coping $(\beta=0.249 ; p=0.000)$ and social support coping $(\beta=0.172 ; p=0.002)$, and there was an inverse relationship with avoidant coping $(\beta=-0.146 ; p=0.019)$, social disengagement $(\beta=-0.140 ; p=0.011)$ and rumination $(\beta=-0.115 ; p=0.055)$.

\section{Structured equation model}

The results of the model fit are summarised in Table 2. It was concluded that the model fitted the data well with a chi-square of 820.75 (459 df); CMIN $/ d f=1.79 ; p=0.00$; $\mathrm{RFI}=0.85 ; \mathrm{NFI}=0.87 ; \mathrm{TLI}=0.93 ; \mathrm{CFI}=0.94 ; \mathrm{RMSEA}=$ 0.05 ; and SRMR $=0.05$. The standardised path coefficient estimates and correlations between the independent variables are summarised in Table 5 and depicted in Figure 2. The nine one-way arrows in the path diagram are indicative of regression coefficients that demonstrate the hypothesised effects of the independent variables on the dependent variable, and the two-way arrows represent the correlation or covariance between the variables.

The model fit revealed that the model explains an estimated $33 \%\left(R^{2}=0.33\right)$ of the variance in coping success.

In terms of relative importance, coping success was mostly explained by cognitive coping $(24.9 \%)$, social support coping $(17.2 \%)$ and vacation time $(10.0 \%)$, and a negative relationship was observed between avoidant coping $(14.6 \%)$, social disengagement $(14.0 \%)$ and rumination $(11.5 \%)$.

The results provided supportive evidence for Hypothesis 2, in that adaptive coping strategies positively and significantly predict coping success. 
TABLE 5: Standardised regression weights and correlations.

\begin{tabular}{|c|c|c|c|c|c|c|c|}
\hline \multicolumn{4}{|c|}{ Standardised regression weights } & \multicolumn{4}{|c|}{ Correlations } \\
\hline Variable & Regression & Factor & Estimate & Factor & Correlation & Factor & Estimate \\
\hline v17 & $\leftarrow$ & SOC & 0.913 & SOC & $\leftrightarrow$ & REL & 0.341 \\
\hline v28 & $\leftarrow$ & SOC & 0.848 & SOC & $\leftrightarrow$ & COG & 0.083 \\
\hline v9 & $\leftarrow$ & SOC & 0.824 & SOC & $\leftrightarrow$ & ACT LEI & 0.253 \\
\hline v59 & $\leftarrow$ & SOC & 0.807 & SOC & $\leftrightarrow$ & VAC TIME & 0.223 \\
\hline v2 & $\leftarrow$ & SOC & 0.666 & SOC & $\leftrightarrow$ & AVOID & -0.063 \\
\hline v53 & $\leftarrow$ & REL & 0.867 & SOC & $\leftrightarrow$ & SOC DIS & -0.175 \\
\hline v40 & $\leftarrow$ & REL & 0.841 & SOC & $\leftrightarrow$ & RUM & 0.060 \\
\hline v30 & $\leftarrow$ & REL & 0.837 & SOC & $\leftrightarrow$ & EMO & 0.491 \\
\hline v21 & $\leftarrow$ & REL & 0.837 & REL & $\leftrightarrow$ & COG & 0.030 \\
\hline v41 & $\leftarrow$ & REL & 0.798 & REL & $\leftrightarrow$ & ACT LEI & 0.404 \\
\hline v48 & $\leftarrow$ & REL & 0.726 & REL & $\leftrightarrow$ & VAC TIME & 0.345 \\
\hline v62 & $\leftarrow$ & COG & 0.862 & REL & $\leftrightarrow$ & AVOID & 0.070 \\
\hline v57 & $\leftarrow$ & COG & 0.790 & REL & $\leftrightarrow$ & SOC DIS & -0.057 \\
\hline v46 & $\leftarrow$ & COG & 0.710 & REL & $\leftrightarrow$ & RUM & -0.055 \\
\hline v26 & $\leftarrow$ & COG & 0.703 & REL & $\leftrightarrow$ & EMO & 0.182 \\
\hline v34 & $\leftarrow$ & COG & 0.623 & COG & $\leftrightarrow$ & ACT LEI & 0.069 \\
\hline v65 & $\leftarrow$ & COG & 0.610 & COG & $\leftrightarrow$ & VAC TIME & -0.005 \\
\hline v37 & $\leftarrow$ & ACT LEI & 0.878 & COG & $\leftrightarrow$ & AVOID & -0.544 \\
\hline v29 & $\leftarrow$ & ACT LEI & 0.866 & COG & $\leftrightarrow$ & SOC DIS & -0.268 \\
\hline v19 & $\leftarrow$ & ACT LEI & 0.791 & COG & $\leftrightarrow$ & RUM & -0.400 \\
\hline v39 & $\leftarrow$ & VAC TIME & 0.877 & COG & $\leftrightarrow$ & EMO & 0.481 \\
\hline $\mathrm{v} 20$ & $\leftarrow$ & VAC TIME & 0.801 & ACT LEI & $\leftrightarrow$ & VAC TIME & 0.424 \\
\hline v51 & $\leftarrow$ & VAC TIME & 0.772 & ACT LEI & $\leftrightarrow$ & AVOID & -0.119 \\
\hline v44 & $\leftarrow$ & AVOID & 0.864 & ACT LEI & $\leftrightarrow$ & SOC DIS & -0.099 \\
\hline v12 & $\leftarrow$ & AVOID & 0.731 & ACT LEI & $\leftrightarrow$ & RUM & -0.101 \\
\hline v42 & $\leftarrow$ & AVOID & 0.606 & ACT LEI & $\leftrightarrow$ & EMO & 0.206 \\
\hline v32 & $\leftarrow$ & SOC DIS & 0.827 & VAC TIME & $\leftrightarrow$ & AVOID & 0.071 \\
\hline v23 & $\leftarrow$ & SOC DIS & 0.820 & VAC TIME & $\leftrightarrow$ & SOC DIS & 0.013 \\
\hline v63 & $\leftarrow$ & SOC DIS & 0.774 & VAC TIME & $\leftrightarrow$ & RUM & 0.010 \\
\hline v60 & $\leftarrow$ & RUM & 0.908 & VAC TIME & $\leftrightarrow$ & EMO & 0.118 \\
\hline v45 & $\leftarrow$ & RUM & 0.696 & AVOID & $\leftrightarrow$ & SOC DIS & 0.534 \\
\hline v8 & $\leftarrow$ & EMO & 0.755 & AVOID & $\leftrightarrow$ & RUM & 0.704 \\
\hline v16 & $\leftarrow$ & EMO & 0.738 & AVOID & $\leftrightarrow$ & EMO & -0.319 \\
\hline Coping success & $\leftarrow$ & SOC & 0.172 & SOC DIS & $\leftrightarrow$ & RUM & 0.531 \\
\hline Coping success & $\leftarrow$ & REL & 0.024 & SOC DIS & $\leftrightarrow$ & EMO & -0.281 \\
\hline Coping success & $\leftarrow$ & COG & 0.249 & RUM & $\leftrightarrow$ & EMO & -0.164 \\
\hline Coping success & $\leftarrow$ & ACT LEI & 0.000 & - & - & - & - \\
\hline Coping success & $\leftarrow$ & VAC TIME & 0.100 & - & - & - & - \\
\hline Coping success & $\leftarrow$ & AVOID & -0.146 & - & - & - & - \\
\hline Coping success & $\leftarrow$ & SOC DIS & -0.140 & - & - & - & - \\
\hline Coping success & $\leftarrow$ & RUM & -0.115 & - & - & - & - \\
\hline Coping success & $\leftarrow$ & EMO & 0.073 & - & - & - & - \\
\hline
\end{tabular}

V, variable; SOC, social support coping; REL, religious coping; COG, cognitive coping; ACT LEI, active leisure coping; VAC TIME, vacation time; AVOID, avoidant coping; SOC DIS, social disengagement; RUM, rumination; EMO, emotional coping.

\section{Discussion}

The purpose of this study was to test a structural model of occupational stress and coping for academics in a HEI in South Africa and determine whether the proposed coping strategies positively and significantly predict coping success. The study contributes towards a more holistic view of coping with occupational stress in academia, especially within the South African higher education context.

\section{Summary of findings}

The results revealed that the theoretically hypothesised model had a good fit with the empirically manifested structural model. The model outlines that academics experience both organisation-specific and job-specific stressors in the institution. Concerning organisation-specific stressors, academics perceive their managers' leadership style and student protest action as extremely stressful, while job-specific stressors were perceived as moderately stressful. Job-specific stressors perceived by academics further include factors intrinsic to the job, career development and progression, interpersonal relationships and a lack of support from management, colleagues and support departments. Work overload, time pressure and administrative demands were, however, perceived as stressful by most academics in the sample. These findings were in agreement with the findings of previous research (Bezuidenhout, 2015; Devonport et al., 2008; Malik et al., 2017; Mudrak et al., 2016). Consequently, academics experience occupational stress (group mean $=7.88$ ) that is mostly related to administrative factors. 


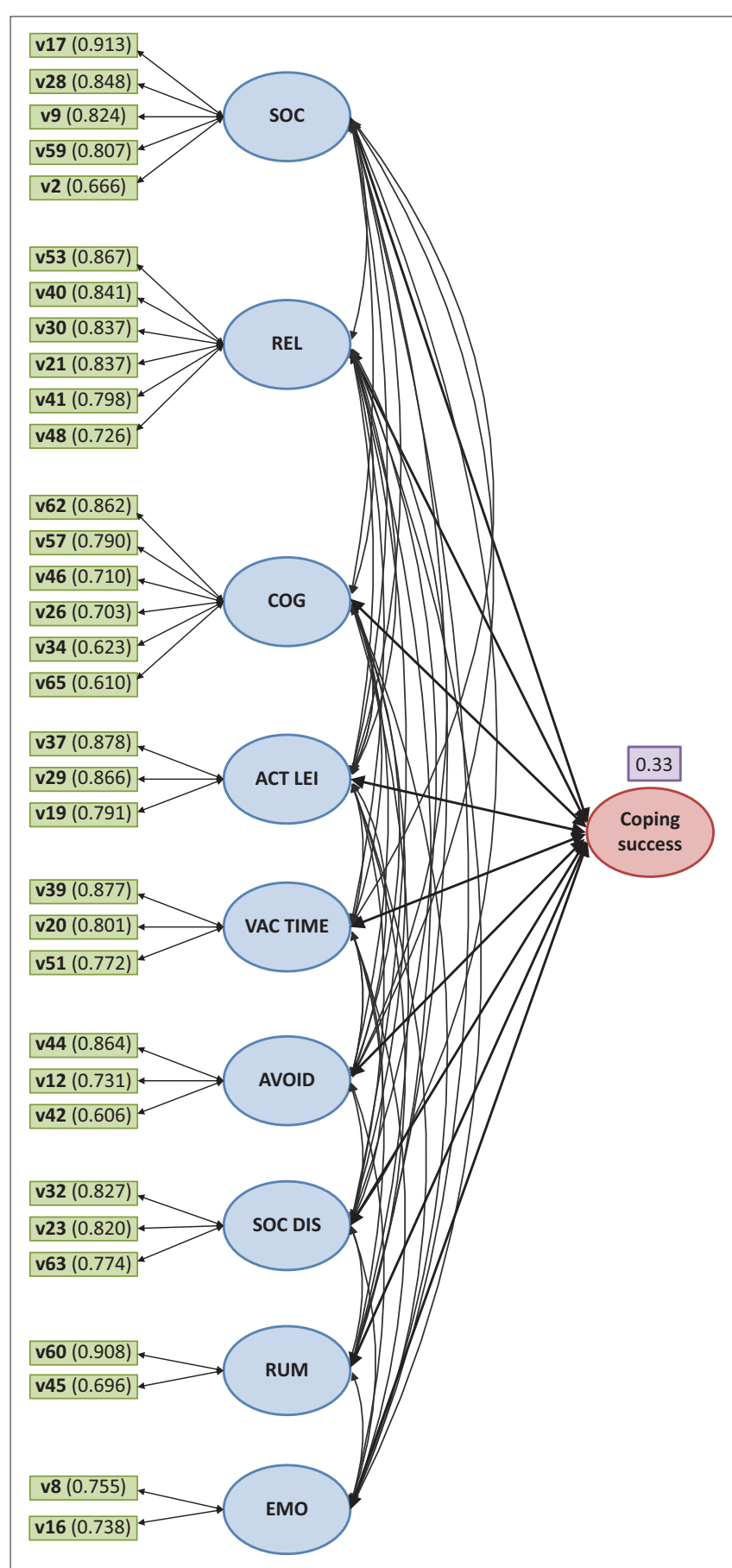

V, variable; SOC, social support coping; REL, religious coping; COG, cognitive coping; ACT LEI, active leisure coping; VAC TIME, vacation time; AVOID, avoidant coping; SOC DIS, social disengagement; RUM, rumination; EMO, emotional coping.

FIGURE 2: Structured equation model.

Secondly, the model reveals that through primary appraisal, emotions are elicited once a stressor is perceived. The results revealed that both organisation-specific and job-specific stressors elicited emotions such as frustration, anxiousness, anger, irritability and helplessness.

Thirdly, once the appraisal of stress-inducing conditions elicits an emotion, coping strategies are adopted to modulate the felt emotion and change the individual's perception of the stressor (Schmidt et al., 2010). Although six coping strategies were identified in literature (Du Plessis \& Martins,
2019), the following nine empirically validated coping strategies emerged: (1) cognitive coping, (2) emotional coping, (3) social support coping, (4) active leisure coping, (5) vacation time, (6) religious coping, (7) avoidant coping, (8) social disengagement, and (9) rumination. The results revealed that the academics mostly adopted adaptive coping strategies (namely cognitive coping, social support coping, and vacation time) to modulate the felt emotions so that their perceptions of the stressor were altered. These findings are supported by previous studies which found that academics adopt adaptive coping strategies to respond to occupational stressors (Darabi et al., 2017; Kersh, 2018; Mark \& Smith, 2012; Mate Siakwa, 2014). Adaptive coping strategies are further associated with coping success and physiological and psychological health and well-being.

Lastly, negative (inverse) relationships were observed between avoidant coping, social disengagement and rumination and coping success. These results imply that academics who adopt maladaptive coping strategies are unable to change the aversive experiences or events that elicit emotions, and continue to experience distress (Holahan, Moos, Holahan, Brennan, \& Schutte, 2005; Newman \& Llera, 2011). Consequently, they will continue to reappraise the stressor until they are able to adopt adaptive coping strategies.

\section{Practical implications of the study}

Given the pervasive nature of occupational stress, the model should allow industrial and organisational psychologists and human resources practitioners in HEIs to gain a deeper understanding of the complexities of the coping process in order to develop and implement wellness practices that prevent occupational stress. Possible interventions concerned with reducing or eliminating stressors inherent in the workplace include:

- redesigning the academic's job to increase academic freedom and autonomy;

- providing adequate resources and support for academics to accomplish goals;

- providing more constructive feedback onjob performance;

- allowing flexibility to meet family and personal needs;

- allowing time off to focus on career development (e.g. research and development leave);

- providing a more supportive work environment;

- consulting and communicating on matters that affect them; and

- reducing the administrative burden by engaging support staff.

Management should further encourage academics to use adaptive coping strategies. It may be useful to arrange stress management courses to introduce them to more appropriate ways of coping with occupational stress (Barkhuizen \& Rothmann, 2008). Cognitive restructuring, problem-solving, time management and planning and critical thinking would be applicable in this context. Furthermore, increasing the availability of resources in the institution would facilitate the 
adoption of adaptive coping strategies (Holton et al., 2016). While adaptive coping strategies are recommended, practitioners should not ignore employees who adopt maladaptive coping strategies, as these employees are at risk of developing psychological disorders. Lastly, HEIs should offer Affect Regulation Training (ART) to improve academics' emotion regulation skills and well-being (Buruck, Dörfel, Kugler, \& Brom, 2016).

\section{Limitations of the study}

The following limitations were encountered in this study: firstly, the literature consulted was mostly of international origin. Secondly, there was little agreement among researchers on the best way to conceptualise these concepts, and the theories discussed were restricted to the seminal work of Lazarus and Folkman which dates back to the late 20th century. Thirdly, although the sample size was sufficient to conduct statistical analyses, further research needs to be conducted among a broader spectrum of participants. Fourthly, a non-probability convenience sample was chosen. The results of the study can therefore not be generalised to other populations. Lastly, a single questionnaire was used to measure all the constructs, so the strength of the relationship between the constructs may be somewhat inflated.

\section{Recommendations for the study}

The author recommends that future researchers explore the moderating effect of individual characteristics (such as personality and locus of control) and external variables (such as social and/or technological changes, and economic and financial conditions) on an academic's ability to cope with occupational stressors.

Furthermore, instead of using a single questionnaire, future researchers could use psychometrically sound questionnaires to further refine the model. Finally, the author recommends that future researchers test the model in other South African industries to minimise the negative spin-off of occupational stress among employees.

\section{Conclusion}

A model for coping with occupational stress in academia was developed. The study revealed that occupational stress among academics could be ascribed to organisation-specific and jobspecific stressors that elicit distressing emotions. Findings further suggest that academics adopt adaptive coping strategies to respond to occupational stressors. The model therefore highlights a number of important aspects that HEIs should consider when identifying interventions to assist academics in coping with occupational stressors.

\section{Acknowledgements}

The author acknowledges the participating institution, and Dr Dion van Zyl for his assistance with the statistical analysis. The author further acknowledges that the research originated from the results of her doctoral thesis.

\section{Competing interests}

The author declares that she had no financial or personal relationship which may have inappropriately influenced her in writing this article.

\section{Author's contributions}

I declare that I am the sole author of this research article

\section{Funding information}

This research received no specific grant from any funding agency in the public, commercial or not-for-profit sectors.

\section{Data availability statement}

Data sharing is not applicable to this article as no new data were created or analysed in this study.

\section{Disclaimer}

The views and opinions expressed in this article are those of the author and do not necessarily reflect the official policy or position of any affiliated agency of the author.

\section{References}

Abbas, S.G., \& Roger, A. (2013). The impact of work overload and coping mechanisms on different dimensions of stress among university teachers. @GRH, 3(8), 93-118. https://doi.org/10.3917/grh.133.0093

Ablanedo-Rosas, J.H., Blevins, R.C., Gao, H., Teng, W.-Y., \& White, J. (2011). The impact of occupational stress on academic and administrative staff, and on students: An empirical case analysis. Journal of Higher Education Policy and Management, 33(5), 553-564. https://doi.org/10.1080/1360080X.2011.605255

Aldao, A., Nolen-Hoeksema, S., \& Schweizer, S. (2010). Emotion-regulation strategies across psychopathology: A meta-analytic review. Clinical Psychology Review, 30(2), 217-237. https://doi.org/10.1016/j.cpr.2009.11.004

Archibong, I.J., Bassey, A.O., \& Effiom, D.O. (2010). Occupational stress sources among university academic staff. European Journal of Educational Studies, 2(3), 217-225. https://doi.org/10.4314/afrrev.v3i2.43639

Babbie, E.R. (2010). The practice of social research (12th edn.). Belmont, CA: Wadsworth

Barkhuizen, N., \& Rothmann, S. (2008). Occupational stress of academic staff in South African higher education institutions. South African Journal of Psychology, 38(2), 321-336. https://doi.org/10.1177/008124630803800205

Bartlett, M.S. (1954). A note on the multiplying factors for various chi square approximations. Journal of the Royal Statistical Society, 16(Series B), 296-298. https://doi.org/10.1111/j.2517-6161.1954.tb00174.x

Baumgartner, H., \& Homburg, C. (1996). Applications of structural equation modelling in marketing and consumer research: A review. International Journal of Research in Marketing, 13(2), 139-161. https://doi.org/10.1016/0167-8116(95)00038-0

Beheshtifar, M., \& Nazarian, R. (2013). Role of occupational stress in organisations. Interdisciplinary Journal of Contemporary Research in Business, 4(9), 648-657.

Bezuidenhout, A. (2015). Implications for academic workload of the changing role of distance educators. Distance Education, 36(2), 246-262. https://doi.org/10.1080/ 01587919.2015.1055055

Broadbent, C. (2013). Idealism confronts realism: University academics coping with change. The European Journal of Social and Behavioural Sciences, 8(1), 13001308. https://doi.org/10.15405/ejsbs.113

Buruck, G., Dörfel, D., Kugler, J., \& Brom, S.S. (2016). Enhancing well-being at work: The role of emotion regulation skills as personal resources. Journal of Occupational Health Psychology, 21(4), 480-493. https://doi.org/10.1037/ocp0000023

Catano, V., Francis, L., Haines, T., Kripalani, H., Shannon, H., Stinger, B., \& Lozanzki, L. (2010). Occupational stress in Canadian universities: A national survey. International Journal of Stress Management, 17(3), 232-258. https://doi. org/10.1037/a0018582

Catell, R.B. (1966). The scree test for number of factors. Multivariate Behavioral Research, 1(2), 245-276. https://doi.org/10.1207/s15327906mbr0102_10

Darabi, M., Macaskill, A., \& Reidy, L. (2017). A qualitative study of the UK academic role: Positive features, negative aspects and associated stressors in a mainly teaching-focused university. Journal of Further and Higher Education, 41 566-580. https://doi.org/10.1080/0309877X.2016.1159287 
Devonport, T.J., Biscomb, K., \& Lane, A.M. (2008). Sources of stress and the use of anticipatory, preventative and proactive coping strategies by higher education lecturers. Journal of Hospitality, Leisure, Sport and Tourism Education, 7(1), lecturers. Journal of Hospitality, Leisure, Sport
70-81. https://doi.org/10.3794/johlste.71.177

Du Plessis, M., \& Martins, N. (2019). Developing a measurement instrument for coping with occupational stress in academia. South African Journal of Industrial Psychology, 45(0), 1-13. https://doi.org/10.4102/sajip.v45i0.1653

Elo, S., \& Kyngäs, H. (2008). The qualitative content analysis process. Journal of Advanced Nursing, 62(1), 107-115. https://doi.org/10.1111/j.1365-2648.2007.04569.x

Field, A. (2013). Discovering statistics using IBM SPSS statistics (4th edn.). London: Sage.

Folkman, S., \& Lazarus, R. (1988). Coping as mediator of emotion. Journal of Personality and Social Psychology, 54(3), 433-475. https://doi.org/10.1037/0022 3514.54.3.466

Furr, R. (2011). Evaluating psychometric properties: Dimensionality and reliability. In Sage library of methods in social and personality psychology: Scale construction Sage library of methods in social and personality psychology: Scale construction and psychometrics for social and personality psychology (pp. 25-52)
Sage. https://0-doi.org.oasis.unisa.ac.za/10.4135/9781446287866.n4

Hair, J.F., Black, W.C., Babin, B.J., \& Anderson, R.E. (2010). Multivariate data analysis (7th edn.). Upper Saddle River, NJ: Pearson Prentice Hall.

Hayes, S.C., Strosahl, K., \& Wilson, K.G. (1999). Acceptance and commitment therapy: An experiential approach to behavior change. New York, NY: Guilford Press.

Holahan, C.J., Moos, R.H., Holahan, C.K., Brennan, P.L., \& Schutte, K.K. (2005). Stress generation, avoidance coping and depressive symptoms: A 10-year model. Journal of Consulting and Clinical Psychology, 73(4), 658-666. https://doi.org/ 10.1037/0022-006X.73.4.658

Holton, M.K., Barry, A.E., \& Chaney J.D. (2016). Employee stress management: An examination of adaptive and maladaptive coping strategies on employee health Work, 53(2), 299-305. https://doi.org/10.3233/WOR-152145

Hu, L., \& Bentler, P.M. (1999). Cutoff criteria for fit indexes in covariance structure analysis: Conventional criteria versus new alternatives. Structural Equation Modelling: A Multidisciplinary Journal, 6(1), 1-55. https://doi.org/10.1080/ 10705519909540118

IBM Corp. (2015). IBM SPSS statistics for windows, version 24.0. Armonk, NY: IBM.

Iqbal, A., \& Kokash, H. (2011). Faculty perception of stress and coping strategies in a Saudi Private University: An exploratory study. International Education Studies, 4(3), 137-149. https://doi.org/10.5539/ies.v4n3p137

Jahanzeb, H. (2010). The impact of job stress on job satisfaction among academic faculty of a mega distance learning institution in Pakistan. A case study of Allama Iqbal Open University. Mustang Journal of Business and Ethics, 1, 31-48.

Johnson, S.J., Willis, S.M., \& Evans, J. (2018). An examination of stressors, strain and resilience in academic and non-academic UK university job roles. Internationa Journal of Stress Management, 26(2), 162-172. https://doi.org/10.1037/str0000096

Kaiser, H. (1970). A second generation little jiffy. Psychometrika, 35(4), 401-415 Retrieved from https://econpapers.repec.org/scripts/redir.pf?u=http $\% 3 \mathrm{~A} \% 2 \mathrm{~F} \%$ 2Fhdl.handle.net $\% 2$ F10.1007\%2FBF02291817; h=repec:spr:psycho:v:35:y:1970:i: 4:p:401-415

Kaiser, H. (1974). An index of factorial simplicity. Psychometrika, 39(1), 31-36. Retrieved from https://econpapers.repec.org/scripts/redir.pf?u=http $\% 3 \mathrm{~A} \% 2 \mathrm{~F} \%$ 2Fhdl.handle.net \%2F10.1007\%2FBF02291575; h=repec:spr:psycho:v:39:y:1974:i 1:p:31-36

Karekla, M., \& Panayiotou, G. (2011). Coping and experiential avoidance: Unique or overlapping constructs? Journal of Behavior Therapy and Experimental Psychiatry, 42(2), 163-170. https://doi.org/10.1016/j.jbtep.2010.10.002

Kersh, R. (2018). Woman in higher education: Exploring stressful workplace factors and coping strategies. NASPA Journal About Woman in Higher Education, 11(1) and coping strategies. NASPA Journal About Woman in High

Kinman, G. (2001). Pressure points: A review of research on stressors and strains in UK academics. Education Psychology: An International Journal of Experimental Educational Psychology, 21(4), 473-492. https://doi.org/10.1080/0144341 0120090849

Ladebo, O., \& Oloruntoba, A. (2005). The effects of stressors, positive affectivity and coping strategies on well-being among academic staff in a Nigerian agricultura university. Acta Academica, 37(3), 212-233. Retrieved from http://journals.ufs. ac.za/index.php/aa/article/view/904
Lazarus, R.S., \& Folkman, S. (1984). Stress appraisal and coping. New York, NY: Springer.

Malik, N.A., Björkqvist, K., \& Österman, K. (2017). Factors associated with occupational stress among university teachers in Pakistan and Finland. Journal of Educational, Health and Community Psychology, 6(2), 1-14. https://doi.org/10.26555/jehcp. v6i2.a7047

Mark, G., \& Smith, A.P. (2012). Effects of occupational stress, job characteristics, coping, and attributional style on the mental health and job satisfaction of university employees. Anxiety, Stress and Coping: An International Journal, 25(1) 63-78. https://doi.org/10.1080/10615806.2010.548088

Martins, N., \& Ungerer, L.M. (2014). Virtual teaching dispositions at a South African open distance-learning university. Procedia: Social and Behavioural Sciences, 171 929-936. https://doi.org/10.1016/j.sbspro.2015.01.211

Mate Siakwa, G. (2014). Sources of stress and coping strategies adopted by academic senior members in the University of Cape Coast. International Journal of Research in Social Sciences, 4(2), 31-39. Retrieved from http://ijsk.org/uploads/ 3/1/1/7/3117743/3_stress_management.pdf

Mudrak, J., Zabrodska, K., Kveton, P., Jelinek, M., Blatny, M., Solcova, I., \& Machovcova, K. (2016). Occupational well-being among university faculty: A job demandresources model. Research in Higher Education, 59, 325-348. https://doi. org/10.1007/s11162-017-9467-x

Newman, M.G., \& Llera, S.J. (2011). A novel theory of experiential avoidance in generalised anxiety disorder: A review and synthesis of research supporting a contrast avoidance model of worry. Clinical Psychology Review, 31(3), 371-382. https://doi.org/10.1016/j.cpr.2011.01.008

Odirile, B.E., Mpofu, E., \& Montsi, M.R. (2009). Career coping and subjective wellbeing among university employees. Perspectives in Education, 27(3), 247-257.

Ongori, H., \& Agolla, J.E. (2008). Occupational stress in organisations and its effects on organisational performance. Journal of Management Research, 8(3), 123-135.

Pargament, K.I., \& Raiya, H.A. (2007). A decade of research on the psychology of religion and coping. Psyke \& Logos, 28, 742-766. Retrieved from http://ojs. statsbiblioteket.dk/index.php/psyke/article/viewFile/8398/6958

Pienaar, C., \& Bester, C.L. (2008). The retention of academics in the early career phase. South African Journal of Human Resource Management, 6(2), 32-41. Retrieved from sajhrm.co.za/index.php/sajhrm/article/download/171/146

Poalses, J., \& Bezuidenhout, A. (2018). Mental health in higher education: A comparative stress risk assessment at an open distance learning university in South Africa. International Review of Research in Open and Distributed Learning, 19(2), 169-190. https://doi.org/10.19173/irrodl.v19i2.3391

Rakshit, M., \& Sharma, Y. (2016). Occupational stress and its impact on physical and psychological health of employees in private educational organisations: Management strategies. International Journal of Advanced Research in Education and Technology, 3(3), 96-101.

Safaria, T., Othman, A.B., \& Wahab, M.N.A. (2010). Religious coping, job insecurity and job stress among Javanese academic staff: A moderated regression analysis. International Journal of Psychological Studies, 2(2), 159-169. https://doi. org/10.5539/ijps.v2n2p159

Salkind, N.J. (2010). Encyclopedia of research design. Thousand Oaks, CA: Sage.

Schmidt, S., Tinti, C., Levine, L.J., \& Testa, S. (2010). Appraisals, emotions and emotion regulation: An integrative approach. Motivation and Emotion, 34, 63-72. https:// doi.org/10.1007/s11031-010-9155-z

Slišković, A., \& Maslić Seršič, D. (2011). Work stress among university teachers: Gender and position differences. Archives of Industrial Hygiene and Toxicology 62(4), 299-307. https://doi.org/10.2478/10004-1254-62-2011-2135

Stevenson, A., \& Harper, S. (2006). Work stress and student learning experience Journal of Quality Assurance in Education, 14(2), 167-178. https://doi org/10.1108/09684880610662042

Steyn, G.M., \& Kamper, G. D. (2006). Understanding occupational stress among educators: An overview. Africa Education Review, 3(1+2), 113-133. https://doi. org/10.1080/18146620608540446

Vokić, N.P., \& Bogdanić, A. (2008). Individual differences and occupational stress perceived: A Croatian study. Zagreb International Review of Economics and Business, 11(1), 61-79. https://hrcak.srce.hr/78599

Watkins, M.W. (2018). Exploratory factor analysis: A guide to best practice. Journal of Black Psychology, 44(3), 219-246. https://doi.org/10.1177/0095798418771807 